\title{
CHF Phenomena by Photographic Study of Boiling Behavior due to Transient Heat Inputs
}

\author{
Jongdoc Park, ${ }^{1}$ Katsuya Fukuda, ${ }^{2}$ and Qiusheng Liu ${ }^{2}$ \\ ${ }^{1}$ Oshima National College of Maritime Technology, 1091-1 Komatsu, Suo-Oshima-cho, Oshima-gun, Yamaguchi 742-2106, Japan \\ ${ }^{2}$ Graduate School of Maritime Sciences, Kobe University, 5-1-1 Fukueminami, Higashinada, Kobe 658-0022, Japan \\ Correspondence should be addressed to Jongdoc Park, park@oshima-k.ac.jp
}

Received 7 May 2012; Revised 31 August 2012; Accepted 18 September 2012

Academic Editor: Eckhard Krepper

Copyright ( $) 2012$ Jongdoc Park et al. This is an open access article distributed under the Creative Commons Attribution License, which permits unrestricted use, distribution, and reproduction in any medium, provided the original work is properly cited.

\begin{abstract}
The transient boiling heat transfer characteristics in a pool of water and highly wetting liquids such as ethanol and FC-72 due to an exponentially increasing heat input of various rates were investigated using the $1.0 \mathrm{~mm}$ diameter experimental heater shaped in a horizontal cylinder for wide ranges of pressure and subcooling. The trend of critical heat flux (CHF) values in relation to the periods was divided into three groups. The CHF belonging to the 1st group with a longer period occurs with a fully developed nucleate boiling (FDNB) heat transfer process. For the 2nd group with shorter periods, the direct transition to film boiling from non boiling occurs as an explosive boiling. The direct boiling transition at the CHF from non-boiling regime to film boiling occurred without a heat flux increase. It was confirmed that the initial boiling behavior is significantly affected by the property and the wettability of the liquid. The photographic observations on the vapor bubble behavior during transitions to film boiling were performed using a high-speed video camera system.
\end{abstract}

\section{Introduction}

Understanding of the transient boiling heat transfer and CHF phenomena caused by increasing heat inputs in subcooling water at high pressures is necessary to predict the likelihood of a severe, design-based accident in a water-cooled nuclear reactor. The typical trend of the CHF values in relation to the heat generation rates shown with period is as follows: the CHF gradually increases to a maximum value from a steady-state CHF, and then the CHF quickly decreases to a minimum value, and finally, the CHF again increases, accompanied by a decrease in period. The steady-state CHF corresponds to the CHF due to the heat input with a period $\tau$ of $20 \mathrm{~s}$. This trend suggests that there exists another mechanism of CHFs for shorter periods different from the thermalhydrodynamic instability (HI) model firstly suggested by Kutateladze [1] and Zuber [2]. The CHFs for the shorter periods at which direct or semi direct transitions to film boiling occurred in transient conduction regime due to a quasi-steadily increasing or increasing heat input for the liquids including water. A direct transition from non boiling convective regime to film boiling one was reported by
Avksentyuk and Mamontova [3] and Kutateladze et al. [4] in liquid metals and wetting liquids as some peculiarities of CHF. However, A few key aspects of the complex CHF phenomena for the heat inputs with short periods are as yet not fully understood.

The direct transition from a non-boiling regime such as natural convection and transient conduction regimes to film boiling without nucleate boiling was observed by Sakurai et al. $[5,6]$. They carried out the experiments of the CHFs for the heat inputs with various periods on a platinum horizontal cylinder in liquid nitrogen at various pressures and found that direct transition to film boiling occurred in transient conduction regime. The transition mechanism to film boiling was confirmed by a photographic study on the vapor bubble and vapor film behavior on the cylinder surface by Sakurai et al. [7]. They concluded by the photographs that the semi-direct transition from conduction regime to film boiling with nucleate boiling due to the rapidly increasing heat inputs in water occurs due to heterogeneous spontaneous nucleation (HSN) in originally flooded cavities with or without nucleate boiling at around the lower limit of HSN surface superheat. 
The measured CHFs related to subcoolings for water, liquid nitrogen, and liquid helium with pressures as a parameter disagreed with the corresponding values derived from the existing correlations given by Kutateladze [1] based on the model of CHF resulting from hydrodynamic instability. However, those data were well described by the newly derived subcooled pool boiling CHF correlations derived by Sakurai et al. [6] by assuming that CHFs occur due to the hydrodynamic instability (HI), or the heterogeneous spontaneous nucleation (HSN) in originally flooded cavities with liquid on the experimental heater surface. Chang et al. [8] measured CHF and corresponding surface superheat at which the transition from natural convection regime to film boiling in a pool of FC-87 occurs and also measured minimum film boiling heat flux and corresponding surface superheat. They concluded that the film boiling incipience at the transition point and minimum film boiling at collapse point occur due to the lower limit of HSN in wetting liquid of FC72 and FC-87. Fukuda et al. [9] investigated the effect of the surface conditions of the platinum experimental cylinders in a pool of water on the two different surface conditions with mirror surface (MS) finished using alumina suspension and rough surface (RS) finished using the \#3 emery paper. As the result, it was confirmed that the photographs of vapor bubbles and film behavior during transitions to film boiling in water were not different with each other not only for quasisteadily increasing heat input but also for rapidly increasing one. Recently, the pool boiling CHF for various liquids using a $1.0 \mathrm{~mm}$ diameter platinum horizontal cylinder was measured to investigate the boiling behavior of transient phenomena [10]. It was confirmed that the vapor film behavior during transition to fully developed nucleate boiling or direct transition at the CHF to film boiling was significantly affected by the properties of boiling liquid and the wettability between liquids and surface of heater. However the mechanism has not been clarified yet.

The present work is to make clear the transition phenomena to film boiling at steady and transient CHF in nonwetting and wetting liquids. The generalized phenomena for the transitions to film boiling from single-phase conduction or transient conduction and fully or insufficiently developed nucleate boiling due to exponential heat generation rates for wide range of subcoolings and pressures were investigated in water, ethanol, and FC-72, adding the photographic approach on the vapor bubble and vapor film behavior on the cylinder surface by using a high-speed video camera.

\section{Experimental Apparatus and Method}

2.1. Pool Boiling Apparatus. The schematic diagram of the experimental apparatus is shown in Figure 1. It mainly consists of a boiling vessel, an experimental heater shaped in a horizontal cylinder, a pressurizer, a device to control the heat generation rate, a data measurement and processing system, and a high-speed video camera.

The boiling vessel has inspection windows and is made of stainless steel; it has an inner diameter of $200 \mathrm{~mm}$ and a height of $600 \mathrm{~mm}$. The experimental heater is made of platinum wire and is a diameter of $1.0 \mathrm{~mm}$ which is horizontally mounted in the vessel. The effective length of the heater between the potential taps is about $31 \mathrm{~mm}$. The heater was annealed in order to maintain an even properties and its electrical resistance versus temperature relation was calibrated in water and glycerin baths using a precision double bridge circuit. The calibration accuracy was estimated to be within $\pm 0.5 \mathrm{~K}$.

\subsection{Experimental Method and Procedure. The experimental} heater was heated electrically by using a fast response, direct current source (max. $700 \mathrm{~A}$ ) controlled by a digital computer so as to give a desired time function for the heat input. The average temperature of the heater was measured by resistance thermometry using the heater itself. A double bridge circuit with the heater as a branch was first balanced at the bulk liquid temperature. The output voltages of the bridge circuit, together with the voltage drops across the potential taps of the heater and across a standard resistance, were amplified and passed through analog-to-digital (A/D) converters installed in the computer. These voltages were simultaneously sampled at a constant time interval that was changed depending on the period. The fastest sampling speed of the A/D converter is $5 \mu \mathrm{s} /$ channel. The average temperature between the potential taps was obtained by using the previously calibrated resistance-temperature relation. The heat generation rate of the heater was determined from the current to the heater and the voltage difference between potential taps on the heater. The surface temperature was obtained by solving the conduction equation in the heater under the conditions of the average temperature and heat generation rate. The instantaneous surface heat flux was obtained from the heat balance equation for a given heat generation rate. The $\mathrm{CHF}$ was determined at a start point where the average temperature rapidly increases up to the preset temperature by using a burnout detector. The analog computer computes the instantaneous mean temperature of the heater and it cuts off the power supply automatically. The experimental error was estimated to be about $\pm 1 \mathrm{~K}$ in the heater surface temperature and $\pm 2 \%$ in the heat flux. A high-speed video camera system (1000 frames/s with a rotary shutter exposure of $1 / 10000 \mathrm{~s}$ ) was used to observe the boiling phenomena and to confirm the start of boiling on the heater surface. The liquid used in the experiment was degassed by keeping them boiling at least for 30 minutes in the liquid feed tank. Vapor was recovered to the pool with a water-cooled condenser. The liquid was fully filled in the boiling vessel with the free surface only in the pressurizer and liquid feed tank. Liquid temperatures in the boiling vessel and in the pressurizer were separately controlled to realize the desired saturated and subcooled conditions. Each heat flux and surface superheat was calculated by the data processing system according to time. The heat input was raised with exponential function, $Q=Q_{0} \exp (t / \tau)$. $Q_{0}$ is initial heat generation rate, $t$ is time, and $\tau$ is period. Period $\tau$ is an e-fold time that corresponds to heat generation rate with the exponential increasing rate. In this study, heat transfer processes for the periods longer than $10 \mathrm{~s}$ are considered as quasi-steady-state one, because the non-boiling region well agreed with natural convection curve, and all CHFs 


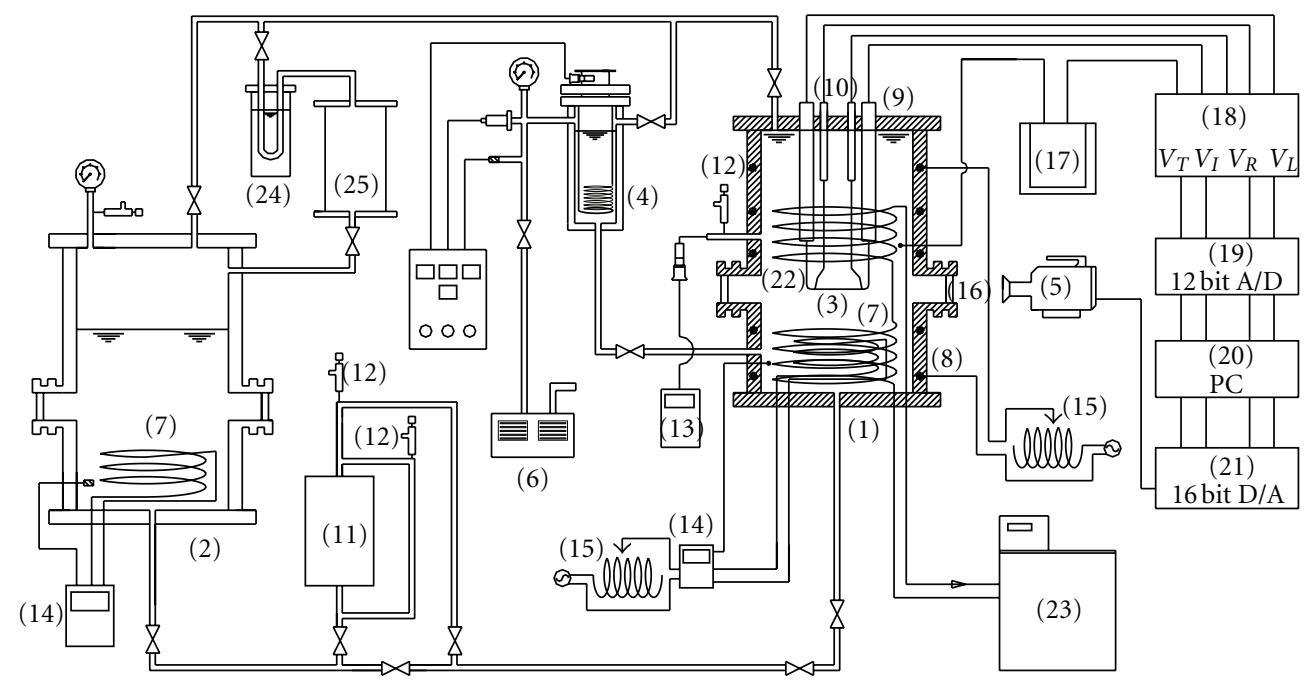
(1) Boiling vessel
(14) Temperature controller
(2) Auxiliary tank
(15) Slide rheostat
(3) Experimental heater
(16) Observation window
(4) Pressurizer
(17) Cold junction
(5) High-speed video camera
(18) Heating system
(6) Vacuum pump
(19) A/D converter
(7) Sheathed heater
(20) Personal computer
(8) Microheater
(21) D/A converter
(9) Current conductor
(22) Spiral cooling tube
(10) Potential conductor
(23) Cooler
(11) Pressure pump
(24) Condenser
(12) Pressure relief valve
(25) Receive tank
(13) Pressure gauge

FIGURE 1: Schematic diagram of experimental apparatus.

TABLE 1: Experimental condition.

\begin{tabular}{lc}
\hline Parameter & Condition \\
\hline Heater & Platinum wire \\
Liquid & Ethanol, water, FC-72 \\
Pressure & $101.3 \mathrm{kpa}-1082 \mathrm{kpa}$ \\
Subcooling & $0 \mathrm{~K}-60 \mathrm{~K}$ \\
Period & $0.005 \mathrm{~s}-20 \mathrm{~s}$ \\
\hline
\end{tabular}

measured for the heat inputs with periods longer than $10 \mathrm{~s}$ are almost the same. Table 1 shows the experimental conditions.

2.3. Typical Boiling Heat Transfer Process. Figure 2 shows typical changes in the wall temperature of platinum wire, $T_{w}$, and heat flux, $q$, with time for an exponential heat generation rate, $Q$, with a period of $8.2 \mathrm{~s}$ at a pressure of $494 \mathrm{kPa}$ under saturated conditions in ethanol. The heat flux, $q$, increases with an exponential increase in the heat generation rate, $Q$.
After the point when boiling begins, $q_{\text {in }}$, the heat flux, shows a rapid overheating and decrease regime caused by a bump of vapor bubbles and liquid flow on the cylinder surface. The $q$ increases again exponentially to reach the critical heat flux point, $q_{\text {cr }}(=\mathrm{CHF}) . T_{w}$ also increases with an increase in $Q$. $T_{w}$ continues to increase up to $T_{\mathrm{ov}}$ (called the overshot point) then rapidly decreases before increasing once again, this time at a low rate. When $q$ reaches CHF, $T_{w}$ rapidly increases with time.

Figure 3 shows the typical boiling curve on a graph of $\log q$ versus $\log \Delta T_{\text {sat }}$ for the experimental run shown in Figure 2. The surface superheat $\Delta T_{\text {sat }}$ is defined by the difference between the surface temperature, $T_{w}$, of the heater and the saturation temperature, $T_{\text {sat }}$, of liquid corresponding to the system pressure. As shown in the figure, heat flux, $q$, increases at a rate on the natural convection curve [11] in a non-boiling regime. After $q_{\text {in }}$, the incipience of boiling, the surface superheat rapidly decreases, and $q$ increases along the fully-developed nucleate boiling (FDNB) regime and reaches the CHF point, $q_{\mathrm{cr}}$. At that point, the transition to film boiling occurs. 


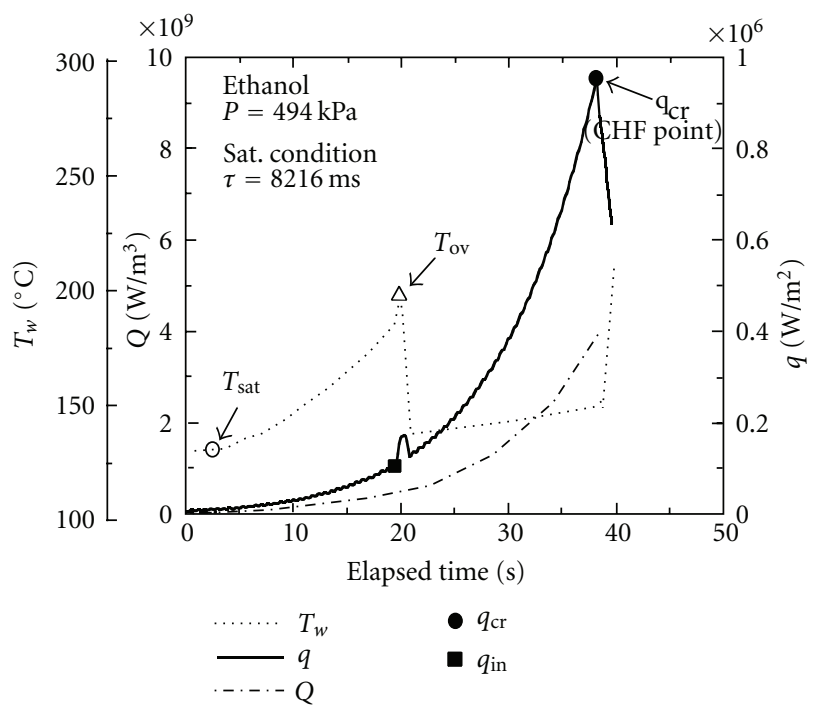

Figure 2: Illustrative time traces of heat generation rate, $Q$; wall temperature of wire, $T_{w}$; and heat flux, $q$.

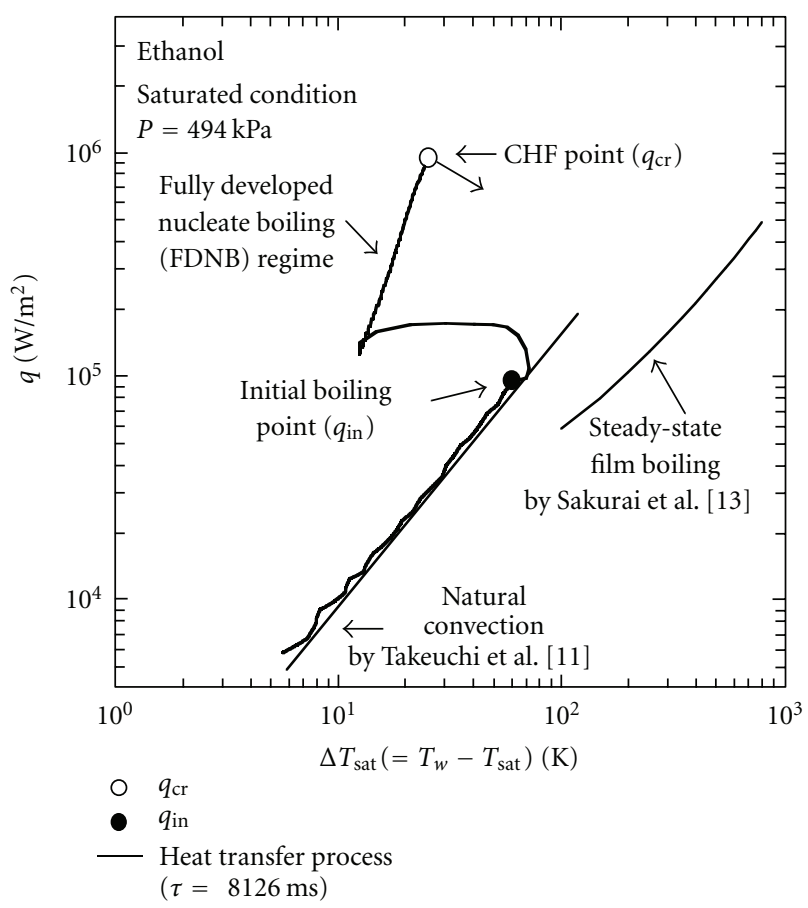

FIGURE 3: Boiling heat transfer process from non-boiling to fully developed nucleate boiling.

\section{Experimental Results and Discussion}

\subsection{Typical Boiling Heat Transfer in Ethanol}

3.1.1. Direct Transition Phenomenon. Figure 4 shows the transient phenomenon on a graph of heat flux, $q$, versus surface superheat, $\Delta T_{\text {sat }}$, at a pressure of $101.3 \mathrm{kPa}$ and a period of $0.1 \mathrm{~s}$ in saturated ethanol. The surface superheat $\Delta T_{\text {sat }}$ is defined by the difference between the surface temperature,

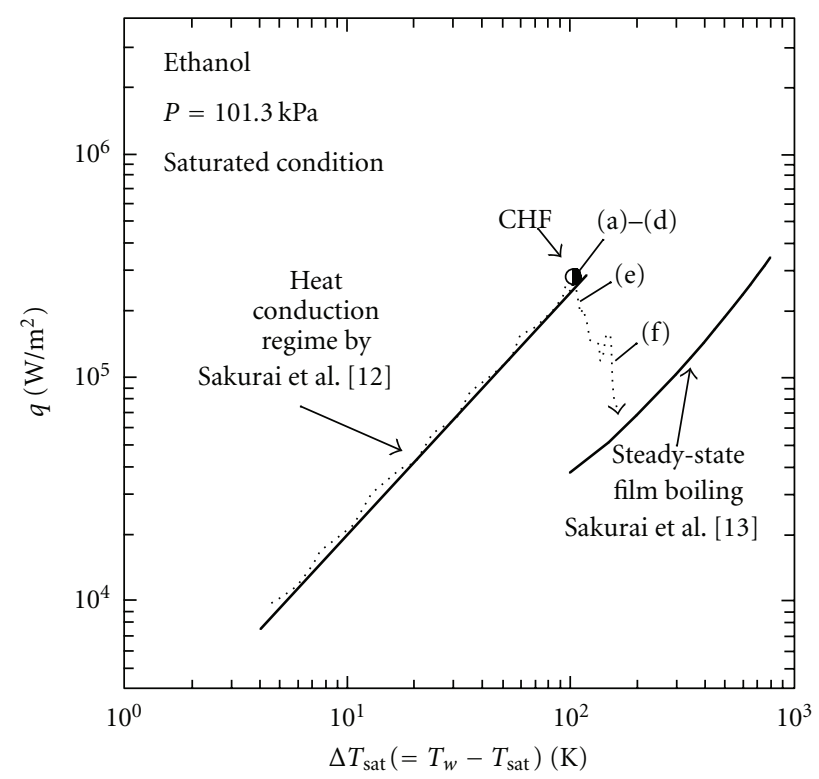

Heat transfer process

- $q_{\text {in }}=q_{\text {cr }}$ $\tau=0.1 \mathrm{~s}$

FIGURE 4: Boiling heat transfer processes from non-boiling to film boiling under saturated condition in ethanol. Photographs shown in Figure 5 were taken at points of Figures 5(a) to 5(f) on the graph.

$T_{w}$, of the heater and the saturation temperature, $T_{\text {sat }}$, of liquid corresponding to the system pressure. The heat conduction curve derived by Sakurai and Shiotsu [12], and the steady-state film boiling curve derived by Sakurai et al. [13] are also shown in the figure for comparison. The boiling process caused by an exponentially increasing heat input with a period of $0.1 \mathrm{~s}$ at atmospheric pressure shows that the $q$ value increases along the natural convection heat transfer curve, and the boiling occurs at a surface superheat point of $100 \mathrm{~K}$, and then shows a transition directly to film boiling without passing the nucleate boiling. The initial boiling temperature gradually decreased with an increase in system pressure based on experimental data. It is considered that the direct boiling transition on the heater surface from nonboiling to film boiling is due to the heterogeneous spontaneous nucleation (HSN) in previously flooded cavities on heater surface as suggested by Sakurai et al. $[5,6,14]$.

Figure 5 gives a series of subsequent photographs from the moment of onset of a vapor phase to film boiling on a surface at a pressure of $101.3 \mathrm{kPa}$ in saturated ethanol. Figure 5(a) is the onset of boiling on the cylinder. Figure 5(b) taken at $1 \mathrm{~ms}$ after the first one shows a vapor tube due to the explosive-like HSN in flooded cavities, and it covers the whole cylinder surface by the large vapor tube. Figure 5(c) taken at $2 \mathrm{~ms}$ after the first one shows thick vapor film concentrically covering the cylinder. The vapor bubbles are very rapidly growing and completely covering the surface of the cylinder within just a few milliseconds. The temperature difference of the surface superheat corresponding to Figures 5(a) to 5(c) is almost the same. Figure 5(d) taken 


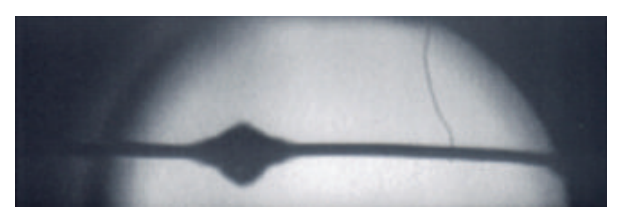

(a) $t=0 \mathrm{~ms}$

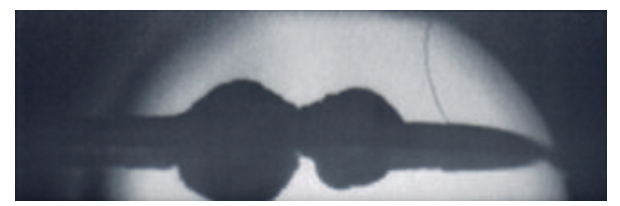

(b) $t=1 \mathrm{~ms}$

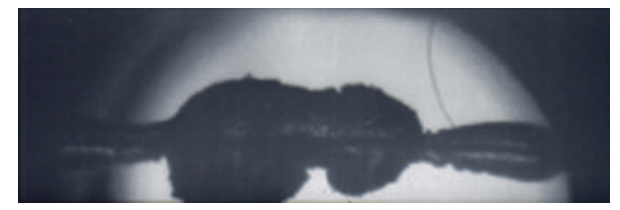

(c) $t=2 \mathrm{~ms}$

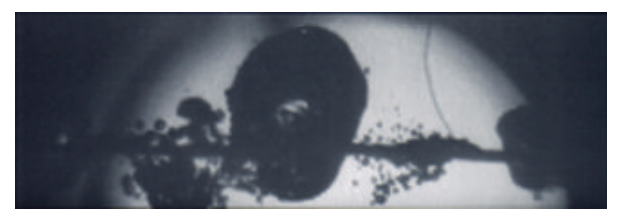

(d) $t=15 \mathrm{~ms}$

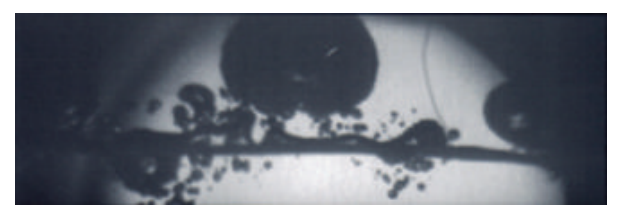

(e) $t=20 \mathrm{~ms}$

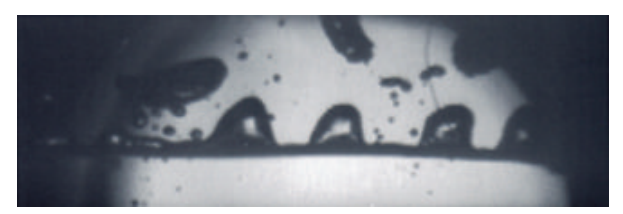

(f) $t=74 \mathrm{~ms}$

FIGURE 5: Vapor film behavior during direct transition to film boiling for a period of $0.1 \mathrm{~s}$ at a pressure of $101.3 \mathrm{kPa}$ in saturated ethanol.

at $15 \mathrm{~ms}$ after the first one shows that the vapor bubbles collapse from the boiling initiation bubbles. Then, large vapor bubbles are broken away from the large vapor film by buoyancy force and move upward as shown in Figure 5(e). After detachment of the large vapor bubbles, solid-liquid contacts occur, and then new thin vapor film with the Taylor unstable wave on the upper part of the vapor-liquid interface covering the cylinder is formed by the explosivelike HSN on the places of solid-liquid contact and thin film boiling. At this moment the surface temperature starts increasing rapidly as a result of heat transfer deterioration. As shown in Figure 5(f), the behavior of vapor-liquid interface in film boiling on the cylinder similar to that for steady-state film boiling on the cylinder is clearly observed after the detachment of large vapor bubbles.

\subsubsection{Boiling Behavior for Wide Range of Pressures under} Saturated Condition. Figure 6 shows vapor film behavior during transition to CHF at each pressure in saturated ethanol. A vertical axis shows heat flux until it reaches the critical heat flux, $q_{\mathrm{cr}}$. It was compared when the fully developed nucleate boiling was occurred with quasi-steadily increasing heat input given by exponential time function. After the incipience of boiling, the tendency to become large vapor bubbles gradually from small ones is almost the same. And it can be confirmed that the diameter of vapor bubbles is small as it becomes high pressure. In 101.3 and $494 \mathrm{kPa}$, the large vapor tube-like explosive boiling is formed rapidly at initiation of boiling. In high pressure $1082 \mathrm{kPa}$, such a phenomenon did not occur but bubbles had spread smoothly from the center. It is because the boiling initiation superheat temperature at low pressure is high compared with that at high-pressure. It is considered that the bubbles are growing rapidly because the large quantity of heat is supplied suddenly from the thick superheated liquid layer covering the cylinder in low-pressure. That is why there is a tendency of foaming from a smaller bubble nucleus while the latent heat of vaporization becomes low, as it becomes high pressure (Sakurai et al. [14]).

The critical heat flux (CHF) in saturated condition was well dependent on system pressure. The diameter of bubbles becomes small by the increase in pressure, and then the supply of liquid to a heating surface becomes better so that transitions to film boiling occurred in higher heat flux.

\subsubsection{Boiling Behavior for Wide Range of Subcoolings at the} Pressure of $494 \mathrm{kPa}$. Figure 7 shows the vapor film behavior during transition to CHF for comparison to each subcooling at a fixed system pressure. It turns out that the vapor bubbles are formed and crushed immediately by low temperature of bulk liquid as the subcooling becomes high. And while heat flux goes up, the natural convection has occurred intensely as shown in the figure.

$\mathrm{CHF}$ was well dependent on the subcooling. As it becomes higher in subcooling, the sensible heat in order that it raises liquid temperature to the saturation temperature corresponding to the system pressure becomes more required, so that $\mathrm{CHF}$ becomes high. Moreover, since the diameter of bubbles becomes small, a heat input continues until the bubbles coalesce in the nucleate boiling region to form coalesced bubbles and transition to film boiling occurs. Therefore, it is thought that CHF increases as it becomes higher in subcooling.

\subsection{Typical Boiling Heat Transfer in Water}

\subsubsection{Heat Transfer Processes under Saturated Condition} in Water. Typical boiling heat transfer processes due to exponentially increasing heat inputs in water are shown in Figure 8 on a graph of heat flux, $q$, versus surface superheat, $\Delta T_{\text {sat }}$. The steady-state natural convection curve derived by Takeuchi et al. [11], the heat conduction curve derived by 


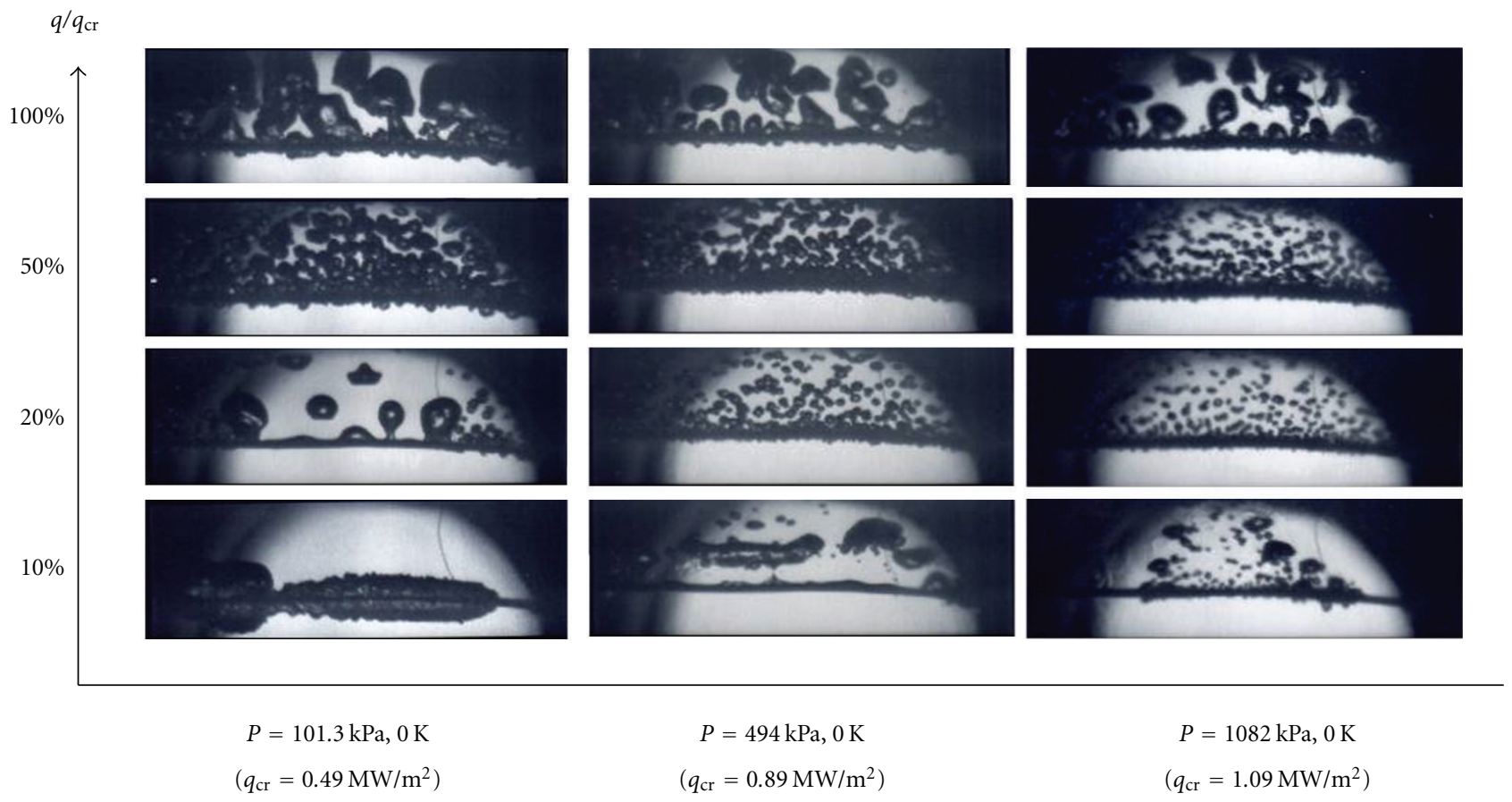

Figure 6: Vapor film behavior during transition to CHF at pressures of $101.3,494$, and $1082 \mathrm{kPa}$ in saturated ethanol due to quasi-steadily increasing heat input given by exponential time function.

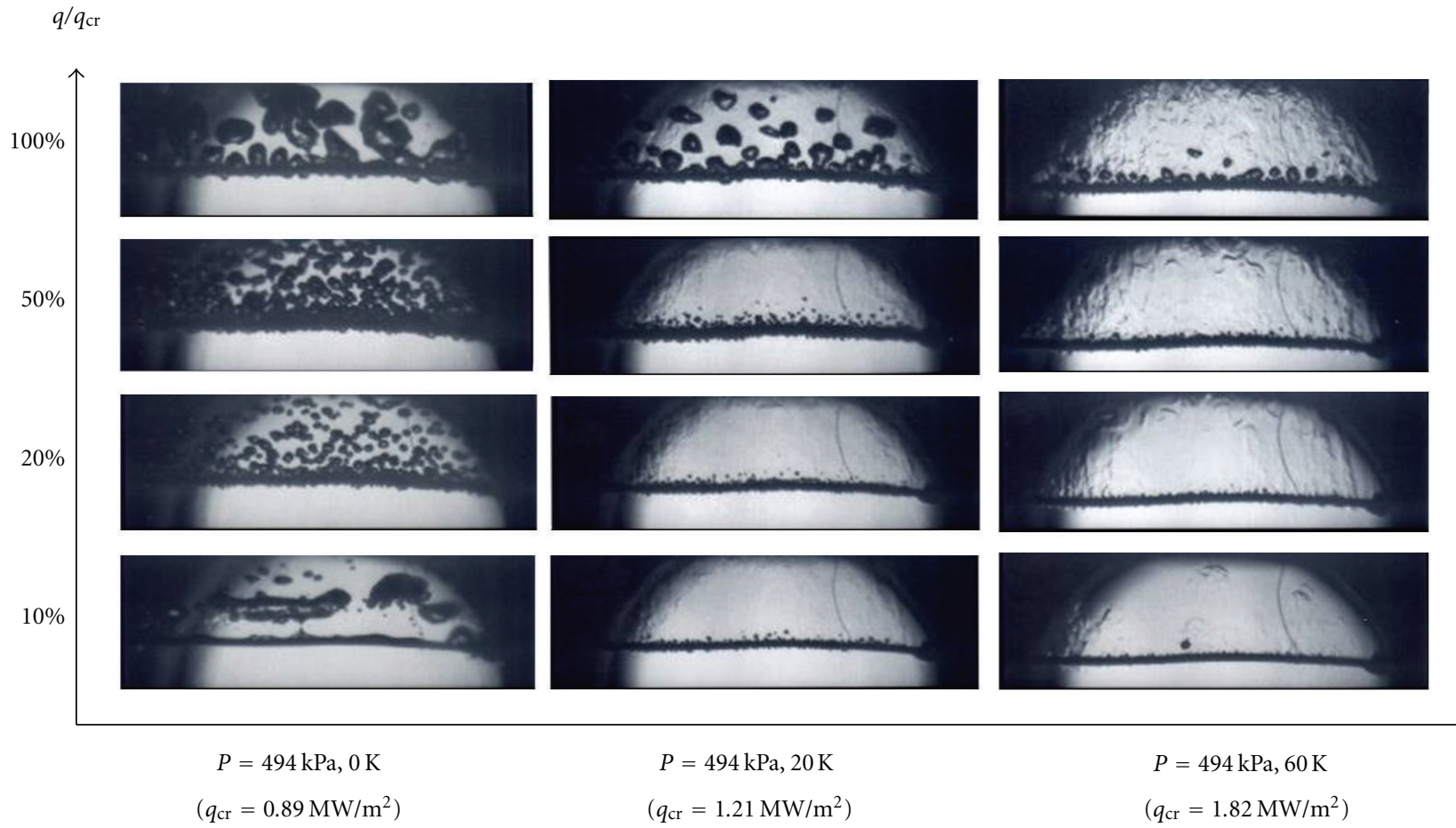

FIGURE 7: Vapor film behavior during transition to CHF at a pressure of $494 \mathrm{kPa}$ for subcoolings of 0, 20 and $60 \mathrm{~K}$ in ethanol due to quasisteadily increasing heat input given by exponential time function. 


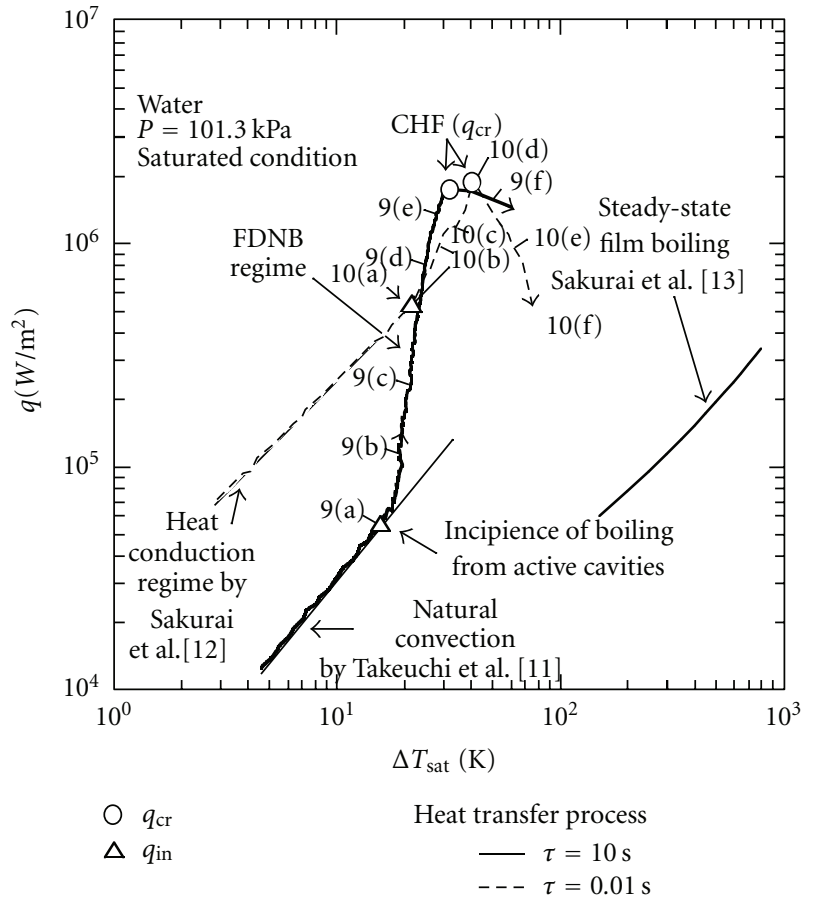

Figure 8: Heat transfer process for period $\tau=10 \mathrm{~s}$ and $0.01 \mathrm{~s}$ at atmospheric pressure in saturated water. Photographs shown in Figures 9 and 10 were taken at points of Figures 9(a) to 9(f) and Figures 10 (a) to 10 (f) on the graph, respectively.

Sakurai and Shiotsu [12] and the steady-state film boiling curve derived by Sakurai et al. [13] are also shown in the figure for comparison.

The heat transfer processes for periods of $10 \mathrm{~s}$ and $0.01 \mathrm{~s}$ at a pressure of $101.3 \mathrm{kPa}$ are shown in the figure. The processes from non-boiling to film boiling are completely different from each other from period to period. It can be found that the processes up to initial boiling heat fluxes, $q_{\text {in }}$, are the natural convection regime for period of $10 \mathrm{~s}$, and the heat conduction regime for period of $0.01 \mathrm{~s}$ as shown in the figure. It is recognized that the values of initial boiling heat flux, $q_{\text {in }}$, increase with a decrease in period; that is, they depend on the increasing rates of heat inputs. When an exponentially increasing heat input is applied to the heater immersed in the pool of water, the heater surface temperature and the heat flux increased. As shown in the figure, the heat transfer processes up to $q_{\text {in }}$ show that heat flux, $q$, for the period of $10 \mathrm{~s}$ increases along the natural convection curve and natural convection heat transfer becomes predominant. As the period shortens, the heat conduction becomes predominant in heat transfer compared with the natural convection.

\subsubsection{Photographs of Vapor Film Behavior during Transition} to Nucleate Boiling in Water. Figure 9 is taken using a highspeed video camera for the vapor behavior on a horizontal cylinder during transition to nucleate boiling due to a slowly increasing heat input for a period of $10 \mathrm{~s}$. The photographs in the figure are shown to confirm the assumptions where the corresponding points on the heat transfer process curve at

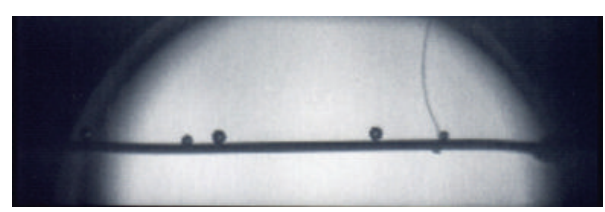

(a) $t=0 \mathrm{~s}$

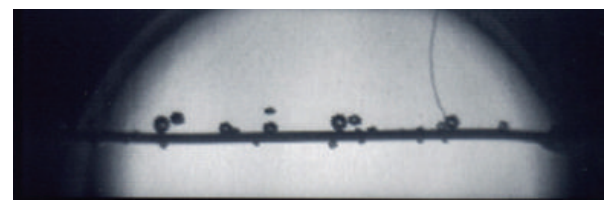

(b) $t=6.8 \mathrm{~s}$

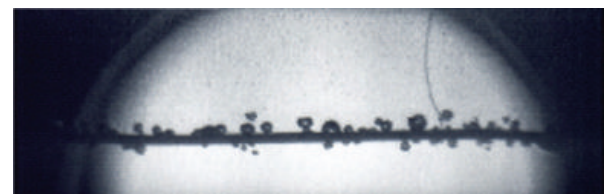

(c) $t=12.8 \mathrm{~s}$

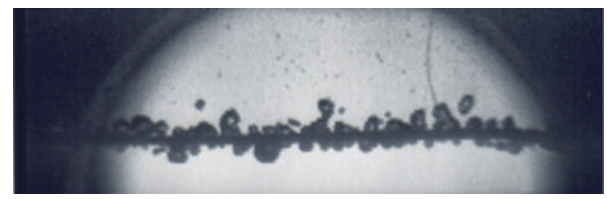

(d) $t=23.6 \mathrm{~s}$

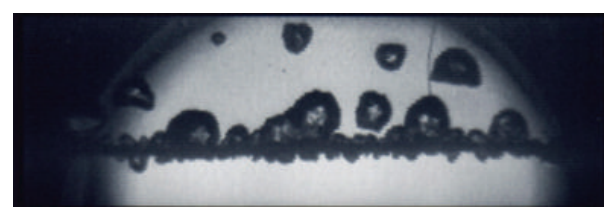

(e) $t=28.2 \mathrm{~s}$

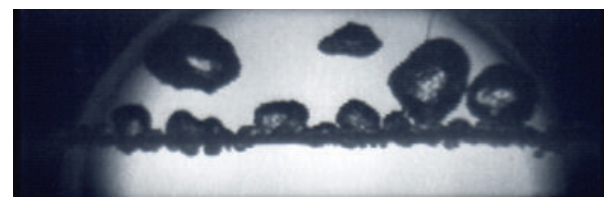

(f) $t=31.2 \mathrm{~s}$

FIGURE 9: Vapor film behavior during transition to fully developed nucleate boiling (FDNB) for a period of $10 \mathrm{~s}$ at atmospheric pressure in saturated water.

the points of Figures 9(a) to 9(f) are shown in Figure 8 with a solid line. Figure 9 (a) is the onset of boiling and it can be seen with a few initial vapor bubbles. Figures 9 (b) and $9(\mathrm{c})$ are the photographs after the time passage of $6.8 \mathrm{~s}$ and $12.8 \mathrm{~s}$ from point (a), respectively. It takes a long time for the vapor bubbles to spread to the whole surface of the experimental heater as shown in the figure. The vapor bubbles around the heater occur from active cavities of entrained vapor that cause the increase of heat flux. After incipient boiling at a point which corresponds to the $q_{\text {in }}$, the surface superheat, $\Delta T_{\text {sat }}$, does not change so much with an increase in heat input. As shown in Figure 9(d), the small bubble nucleus commences to coalesce in the nucleate boiling region to form coalesced bubbles. The detached coalesced bubbles 


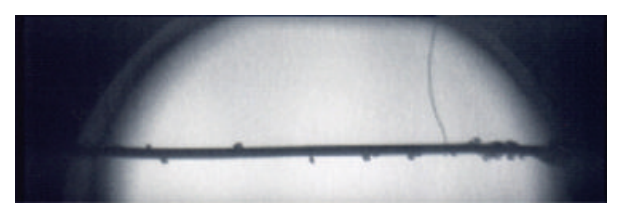

(a) $t=0 \mathrm{~ms}$

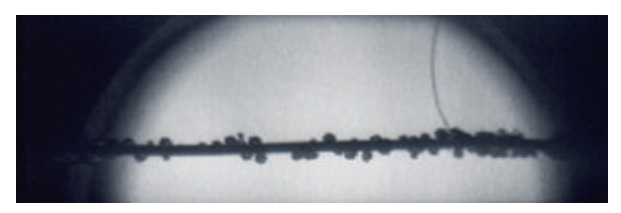

(b) $t=2 \mathrm{~ms}$

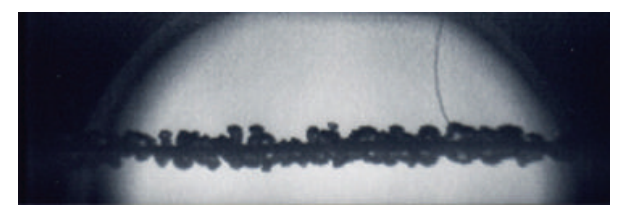

(c) $t=5 \mathrm{~ms}$

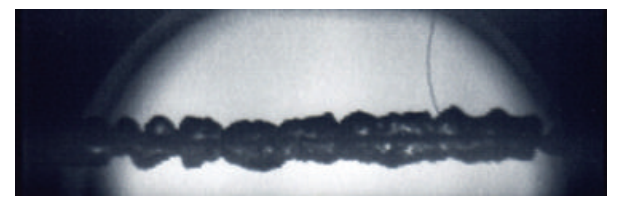

(d) $t=9 \mathrm{~ms}$

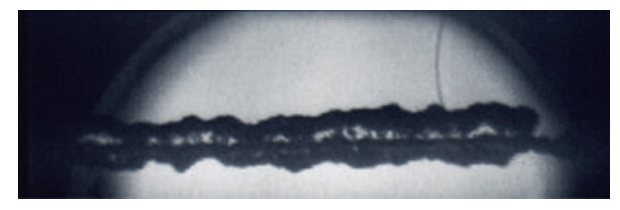

(e) $t=18 \mathrm{~ms}$

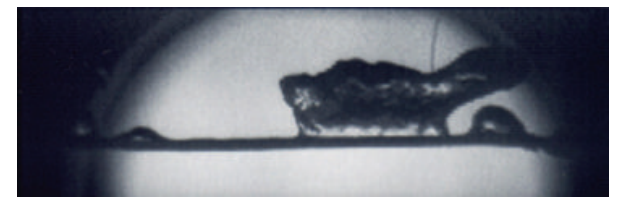

(f) $t=49 \mathrm{~ms}$

Figure 10: Vapor film behavior during semi-direct transition to film boiling for a period of $0.01 \mathrm{~s}$ at atmospheric pressure in saturated water.

continuously increase in size with increases in the heat flux at the points of Figures 9(e) to 9(f).

\subsubsection{Photographs of Vapor Film Behavior during Semidirect} Transition to Film Boiling in Water. Figure 10 shows the semi-direct transition from transient conduction regime to film boiling due to a rapidly increasing heat input for the period of $0.01 \mathrm{~s}$. The CHF almost agrees with the quasisteady-state $\mathrm{CHF}$ for the period of $10 \mathrm{~s}$. The mechanism of semi-direct transition from transient conduction regime to film boiling was not solved for a long time. Sakurai et al. [5, 6] assumed that the mechanism of semi-direct transition to film boiling with slight nucleate boiling from active cavities occurs finally due to the HSN at around the lower limit of HSN surface superheat in originally flooded cavities; the lower limit value was measured under the condition with prepressurization for a quasi-steadily increasing heat inputs. Figures 10 (a) to $10(\mathrm{f})$ are shown to confirm their process. The corresponding points on the heat transfer curve on the $q$ versus $\Delta T_{\text {sat }}$ graph for each photograph are shown in Figure 8 with a dashed line. Figure $10(a)$ is the photograph at point of Figure 10(a), which is the onset of boiling. It shows the cylinder in transient conduction regime with a few initial vapor bubbles. The time, $t$, beside each photograph shows the elapsed time after the time of first photograph, Figure 10(a). Figure 10(b) is the photograph after a time passage of $2 \mathrm{~ms}$ from point (a). Figures 10(b), 10(c), and $10(\mathrm{~d})$ show vapor bubbles around the cylinder occurred from active cavities of entrained vapor which cause the rapid increase of heat flux without the detachment of vapor bubbles. The heat flux for Figure $10(\mathrm{~d})$ is around the CHF. A large vapor film covers the cylinder including all the vapor bubbles from active cavities as shown in Figure 10(d). As seen in Figure 10(e), the large vapor film with the Taylor unstable wave on the top of the vapor film moves upward with a decrease in heat flux and an increase in surface superheat. After that, the large vapor bubbles are separated from the vapor film with the approximate interval of the most dangerous Taylor wave length and levitate in the liquid as seen in Figure 10(f). The heat flux approaches around minimum film boiling heat flux and then increases along the steady-state film boiling heat flux with an increase in surface superheat.

\subsection{Typical Boiling Heat Transfer in FC-72}

\subsubsection{Transient CHF for Period $\tau$ under Saturated Condition.} Figure 11 shows transient CHFs, $q_{\mathrm{cr}}$, for $Q_{0} \exp (t / \tau)$ with the periods, $\tau$, ranging from around $30 \mathrm{~s}$ down to $0.008 \mathrm{~s}$ under saturated FC-72 at atmospheric pressure depending on cylinder surface roughness. Two horizontal experimental heaters of $1.0 \mathrm{~mm}$ in diameter were used. One with no surface preparation and the other one is finished by emery paper. They have the different surface roughness of commercially available surface $(\mathrm{CS}, \mathrm{Ra}=0.11 \mu \mathrm{m})$ and roughly finished surface ( $\mathrm{RS}, \mathrm{Ra}=0.24 \mu \mathrm{m})$, respectively.

In the case of CS cylinder, the $q_{\text {cr }}$ values gradually increase to the maximum value from the steady state CHF, then quickly decrease to the minimum value, and finally increase again accompanied by a decrease in period $\tau$. They are clearly classified into three groups for the period. First group is for the periods longer than $2 \mathrm{~s}$, second group is for the periods shorter than $0.4 \mathrm{~s}$, and third one is for the period between 2 and $0.4 \mathrm{~s}$. In the case of RS cylinder, however, it can be found that there clearly exists an effect of surface roughness; the direct transitions belonging to the second group $q_{\mathrm{cr}}$ occur with remarkable frequency. It means that a range in periods for $q_{\mathrm{cr}}$ of the 2 nd group is changed depending on the surface roughness.

The CHF belonging to the 1st group with a longer period occurs with a fully-developed nucleate boiling (FDNB) heat transfer process. The steady-state CHFs were due to HI. For the 2 nd group with shorter periods, the direct transition 


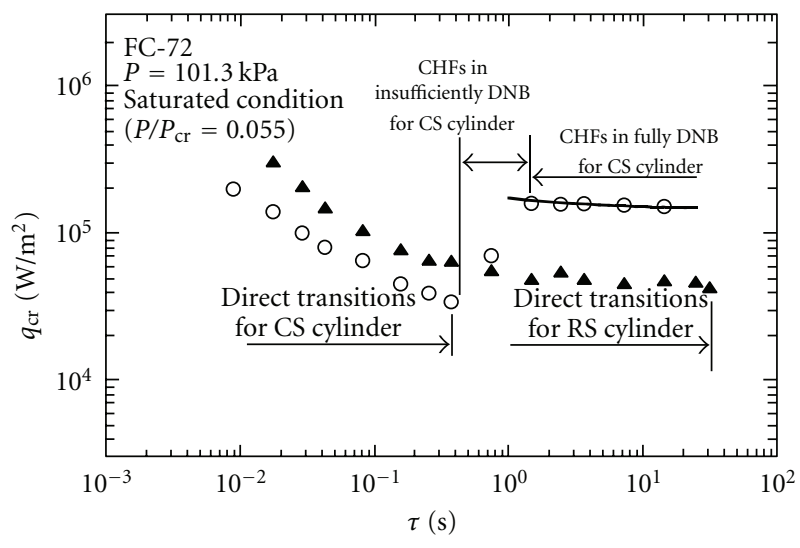

O Commercially available surface (CS) cylinder

- Roughly finished surface (RS) cylinder

- HI curve by Eq.(1)

FIGURE 11: The relation between $q_{\mathrm{cr}}$ and $\tau$ at atmospheric pressure in saturated FC-72 depending on cylinder surface roughness.

to film boiling from non-boiling occurs as an explosive boiling. Fukuda et al. [15] suggested the empirical equation representing transient $\mathrm{CHF}$ values versus periods belonging to the first group in a pool of water. One has

$$
q_{\mathrm{cr}}=q_{\mathrm{st}, \mathrm{sub}}\left(1+0.21 \tau^{-0.5}\right),
$$

where the $q_{\text {st,sub }}$ is given by the quasi-steady-state CHF data in each experiment. Equation (1) is effective for not only water but also the highly wetting liquid such as FC-72 as shown in the figure.

3.3.2. Heat Transfer Processes up to CHFs. Heat transfer processes during transitions to fully-developed nucleate boiling or to film boiling at atmospheric pressure in saturated FC-72 are shown in Figure 12.

In the case of the CS cylinder of roughness, they show the heat transfer processes to film boiling that are completely different from each other due to the exponential period. For the period of $0.02 \mathrm{~s}$, the processes up to initial boiling heat fluxes, $q_{\text {in }}$, are the heat conduction regime derived by Sakurai and Shiotsu [12]. It is considered that the direct boiling transition from non-boiling to film boiling is due to the heterogeneous spontaneous nucleation (HSN) as mentioned before. For the period of $10 \mathrm{~s}$, however, after the incipience of boiling, the nucleate boiling occurs from the residual inert gases which are included into the cavities that are formed after detachment of vapor bubbles with a slight decrease in surface superheat which prevents the growth of the HSN.

On the other hand, in the case of the RS cylinder of roughness for the period of $10 \mathrm{~s}$ as shown with a dashed line, the heat transfer processes up to, $q_{\text {in }}$, show that heat flux, $q$, increases along the natural convection curve derived by Takeuchi et al. [11] in the same process as the CS cylinder. The CHF point is due to the direct transition from singlephase conduction regime to film boiling; the value $q_{\text {in }}$ is equal to $q_{\mathrm{cr}}$. This boiling curve is similar in transition process to the boiling curve for the period of $0.02 \mathrm{~s}$ on CS cylinder.

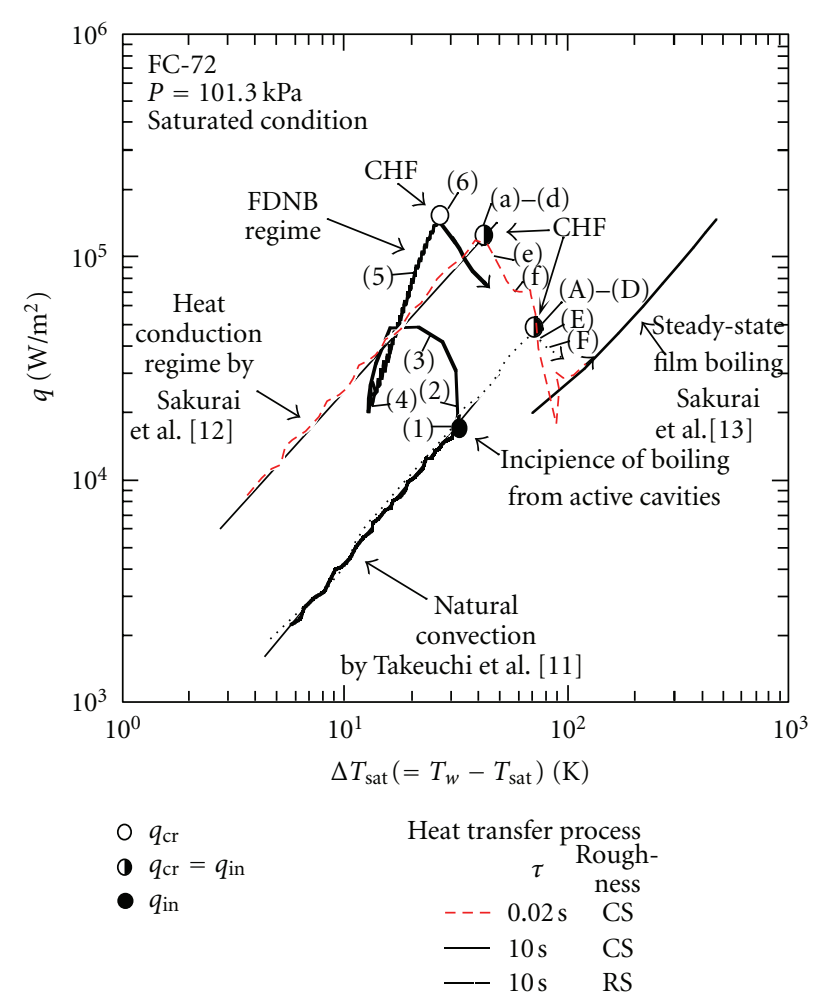

FIGURE 12: Boiling heat transfer processes from non-boiling to film boiling or FDNB at atmospheric pressure in saturated FC-72. Photographs are shown in Figures 13-15.

The boiling occurs at a surface superheat point of $70 \mathrm{~K}$ which is the highest temperature in this experimental scope. It is considered that the direct boiling transitions occur due to the levitation of liquid on the cylinder surface by the explosivelike HSN in originally flooded cavities without contribution of the active cavities entraining vapors. The direct transition is particularly likely to occur in the RS cylinder of roughness.

3.3.3. Photograph Studies in Vapor Behavior. Figure 13 shows the photographs of transient boiling behavior taken by a high-speed video camera at the corresponding points shown in Figure 12. The vapor bubbles are rapidly growing and surrounding the cylinder surface. The rapid growth of vapor bubbles is due to heterogeneous spontaneous nucleation (HSN) within the flooded cavities of cylinder. As shown in the figure, the vapor bubbles covered almost all the heater surface within just a few millisecond. It is seen that the vapor bubbles are separated from the cylinder surface. Figure 13(e) is the photograph of the time at which $15 \mathrm{~ms}$ elapsed from point (a). The film boiling appears after the departure of vapor bubbles. Figure 13(f) is the photograph after the time passage of $42 \mathrm{~ms}$ from point (a) and is the stable film boiling after passing the point (e).

Figure 14 shows the photographs for typical vapor film and vapor bubble behaviors in the transition to developed nucleate boiling corresponding points shown in Figure 12. The large vapor bubbles are rapidly growing and surrounding the cylinder surface, and the cylinder is almost fully 


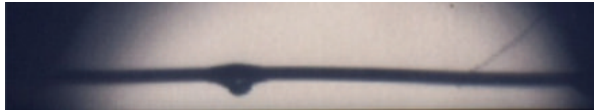

(a) $t=0 \mathrm{~ms}$

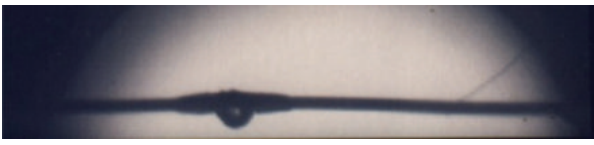

(b) $t=1 \mathrm{~ms}$

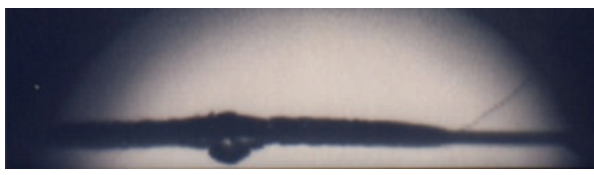

(c) $t=4 \mathrm{~ms}$

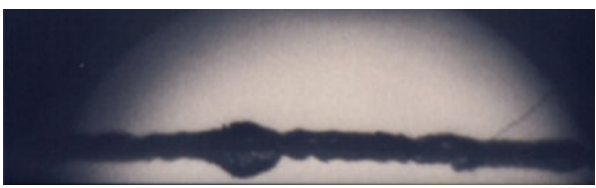

(d) $t=7 \mathrm{~ms}$

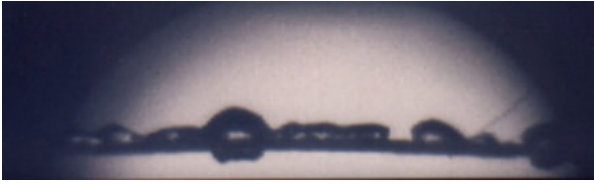

(e) $t=15 \mathrm{~ms}$

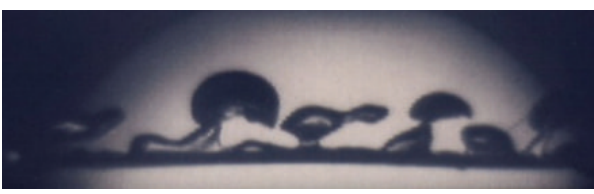

(f) $t=42 \mathrm{~ms}$

FIGURE 13: Vapor film behavior during direct transition to film boiling for a period of $0.02 \mathrm{~s}$ at atmospheric pressure in saturated FC-72 with the CS cylinder.

covered with the vapor bubbles as shown in the Figure 14(b). This vapor film behavior that is rapidly growing and covering the heater surface during boiling initiation could never be seen in the water experiment with quasi-steadily increasing exponential heat input. As seen in Figure 14(c), the nucleate boiling occurs from the cavities of entrained vapor that are formed after detachment of vapor bubbles with a slight decrease in surface superheat which prevents the growth of the HSN. If the detachment of vapor bubbles without decreasing in average surface superheat is realized, the direct or semi-direct transition occurs as in the case of rapidly increasing in heat input mentioned before.

Figure 15 gives a series of subsequent photographs from the moment of onset of a vapor phase to film boiling in experimental condition with RS cylinder. It is caused by slowly increasing heat input with a period of $10 \mathrm{~s}$, and the corresponding heat transfer processes were shown in Figure 12. Figure 15(a) shows the boiling incipience just after natural convection regime. The vapor film behavior shown in

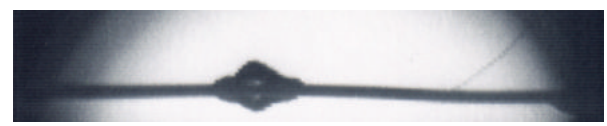

(a) $t=0 \mathrm{~ms}$

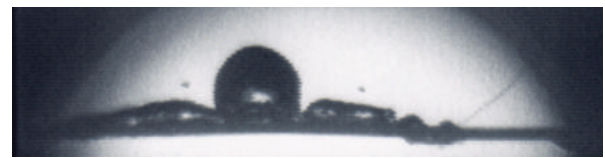

(b) $t=22 \mathrm{~ms}$

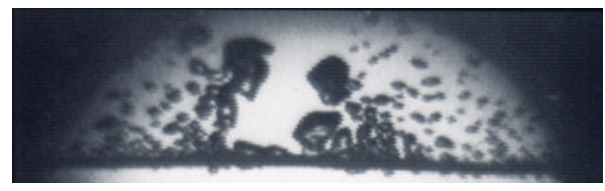

(c) $t=675 \mathrm{~ms}$

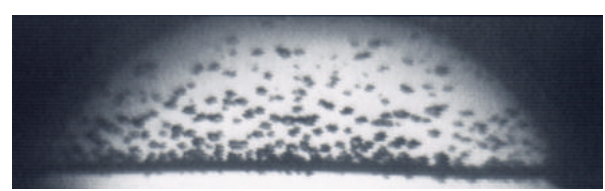

(d) $t=1.9 \mathrm{~s}$

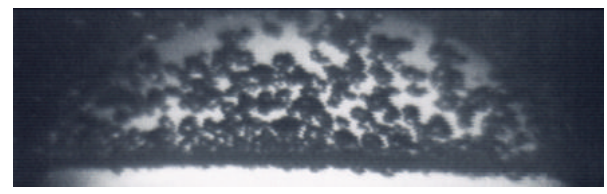

(e) $t=8.8 \mathrm{~s}$

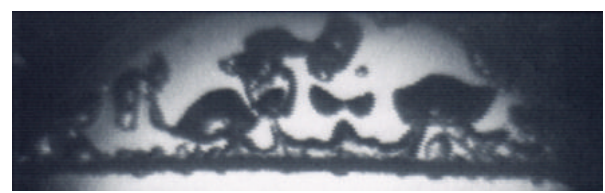

(f) $t=14.2 \mathrm{~s}$

Figure 14: Vapor film behavior during transition to FDNB for a period of $10 \mathrm{~s}$ at atmospheric pressure in saturated FC-72 with the CS cylinder.

Figures 15 (a) to 15 (c) is similar to that of the direct transition of CS cylinder for a period of $0.02 \mathrm{~s}$ in Figure 13. Then a larger vapor tube is rapidly formed around cylinder, the vapor bubbles collapse as shown in Figure 15(d), and they break away from the cylinder surface. After the detachment of the large vapor bubbles, the vapor bubbles are separated from the vapor film with the most dangerous Taylor wave length as shown in Figure 15(f).

\section{Conclusions}

The vapor behavior on the horizontal cylinder during the transition from natural convection and transient conduction regimes to film boiling in water and highly wetting liquids such as ethanol and FC-72 due to various exponentially increasing heat inputs including a quasi-steadily increasing heat input to a rapid increasing one was examined by the photographs taken using a high-speed video camera. 


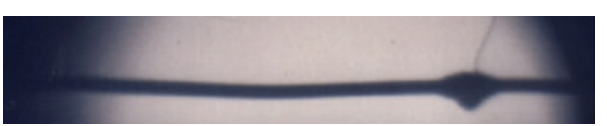

(a) $t=0 \mathrm{~ms}$

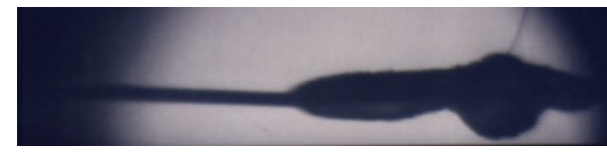

(b) $t=1 \mathrm{~ms}$

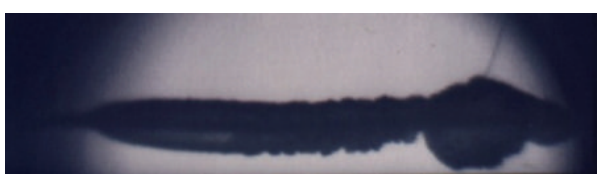

(c) $t=2 \mathrm{~ms}$

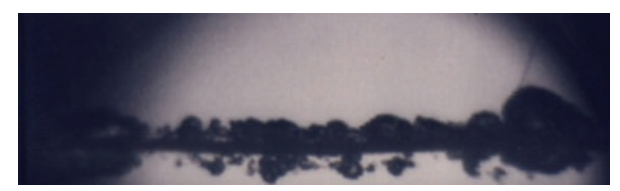

(d) $t=6 \mathrm{~ms}$

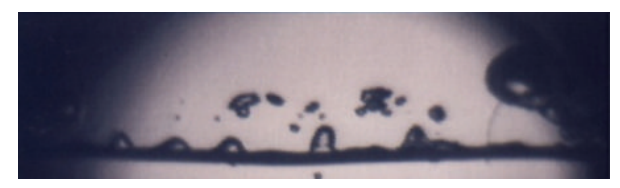

(e) $t=34 \mathrm{~ms}$

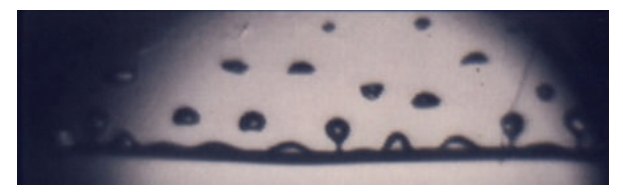

(f) $t=211 \mathrm{~ms}$

Figure 15: Vapor film behavior during direct transition to film boiling for a period of $10 \mathrm{~s}$ at atmospheric pressure in saturated FC72 with the RS cylinder.

In the case of the highly wetting liquids, the vapor film behavior during transition to fully developed nucleate boiling was just similar to that of the direct transition to film boiling. This vapor film behavior that was rapidly growing and covering the heater surface during initial boiling could never be seen in the water experiment with a quasisteadily increasing exponential heat input. It was confirmed that the initial boiling behavior is significantly affected by the property and the wettability of the liquid. The direct transition at the CHF from non-boiling regime to film boiling one occurred without a heat flux increase for a short period within the second group while semi-direct transition occurred with one. It was certain that the direct or semidirect transition occurs in the case of rapidly increasing heat input when the detachment of vapor bubbles without decreasing of average surface superheat is realized. The transient CHFs are clearly divided into three principal groups for the periods.

\section{References}

[1] S. S. Kutateladze, "Heat transfer in condensation and boiling," Tech. Rep. AEC-tr-3770, USAEC, Houston, Tex, USA, 1959.

[2] N. Zuber, "Hydrodynamic Aspects of Boiling Heat Transfer," Tech. Rep. AECU-4439, USAEC, Houston, Tex, USA, 1959.

[3] B. P. Avksentyuk and N. N. Mamontova, "Characteristics of heat transfer crisis during boiling of alkali metals and organic fluids under free convection conditions at reduced pressure," in Proceedings of the Heat ana Mass Transfer Program, vol. 7, pp. 355-362.

[4] S. S. Kutateladze, V. N. Moskvicheva, G. I. Bobrovich, N. N. Mamontova, and B. P. Avksentyuk, "Some peculiarities of heat transfer crisis in salkali metals boiling under free convection," International Journal of Heat and Mass Transfer, vol. 16, no. 4, pp. 705-IN1, 1973.

[5] A. Sakurai and A. Shiotsu, "Heat transfer from a horizontal wire in liquid nitrogen," in Heat Transfer and Super-conduction Magnetic Energy Storage, vol. 211, pp. 7-18, ASME HTD, New York, NY, USA, 1992.

[6] A. Sakurai, M. Shiotsu, and K. Hata, "New transition phenomena to film boiling due to increasing heat inputs on a solid surface in pressurized liquids," in Proceedings of the ASME Winter Annual Meeting, Instability in Two Phase Flow Systems, vol. HTD-260/Fed-169, pp. 27-39, ASME, New York, NY, USA, December 1993.

[7] A. Sakurai, M. Shiotsu, K. Hata, and K. Fukuda, "Photographic study on transitions from non-boiling and nucleate boiling regime to film boiling due to increasing heat inputs in liquid nitrogen and water," Nuclear Engineering and Design, vol. 200, no. 1, pp. 39-54, 2000.

[8] J. Y. Chang, S. M. You, and A. Haji-Sheikh, "Film boiling incipience at the departure from natural convection on flat, smooth surfaces," Journal of Heat Transfer, vol. 120, no. 2, pp. 402-409, 1998.

[9] K. Fukuda, Q. S. Liu, J. D. Park, and H. Kida, "Photographic study on transient critical heat flux depending on surface conditions of test heater in various liquids due to exponentially increasing heat inputs," in Proceedings of 6th International Symposium on Heat Transfer, pp. 511-518, Beijing, China, 2004.

[10] J. Park, "Photographic study o transient phenomena in pool boiling CHF for various liquids," in Proceedings of 7 th International Symposium on Marine Engineering, Tokyo, Japan, October 2005.

[11] Y. Takeuchi, K. Hata, M. Shiotsu, and A. Sakurai, "General correlation for laminar natural convection heat transfer from single horizontal cylinders in liquids and gases with all possible Prandtl numbers," in Proceedings of the ASME International Mechanical Congress and Exposition, vol. HTD-317-1, pp. 259270, ASME, New York, NY, USA, November 1995.

[12] A. Sakurai and M. Shiotsu, "Transient pool boiling heat transfer, Part 1: incipient boiling superheat," ASME Journal of Heat Transfer, vol. 99, no. 4, pp. 547-553, 1977.

[13] A. Sakurai, M. Shiotsu, and K. Hata, "General correlation for pool film boiling heat transfer from a horizontal cylinder to subcooled liquid. Part 2. Experimental data for various liquids and its correlation," Journal of Heat Transfer, vol. 112, no. 2, pp. 441-450, 1990.

[14] A. Sakurai, M. Shiotsu, K. Hata, and K. Fukuda, "Transition phenomena from non-boiling regime to film boiling on a cylinder surface in highly subcooled and pressurized water due to increasing heat inputs," ASME Paper 95-WA/HT-17, 1995. 
[15] K. Fukuda, M. Shiotsu, and A. Sakurai, "Transient pool boiling heat transfer due to increasing heat inputs in subcooled water at high pressures," in Proceedings of the 7th International Meeting on Nuclear Reactor Thermal Hydraulics, pp. 554-573, Saratoga Springs, NY, USA, 1995. 

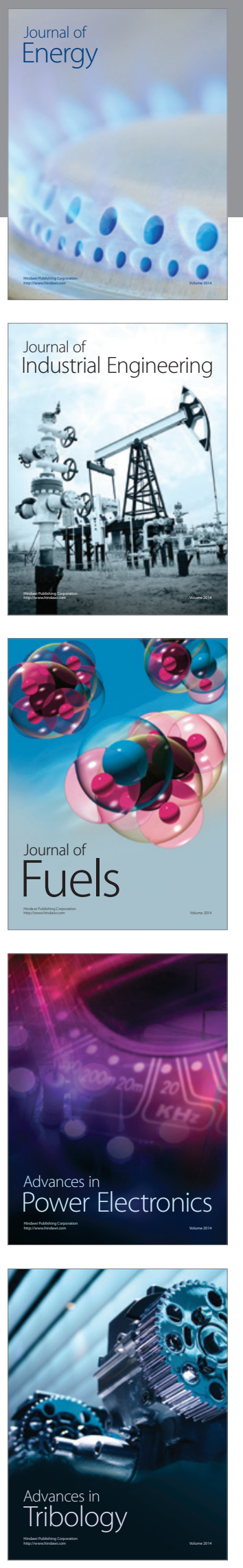
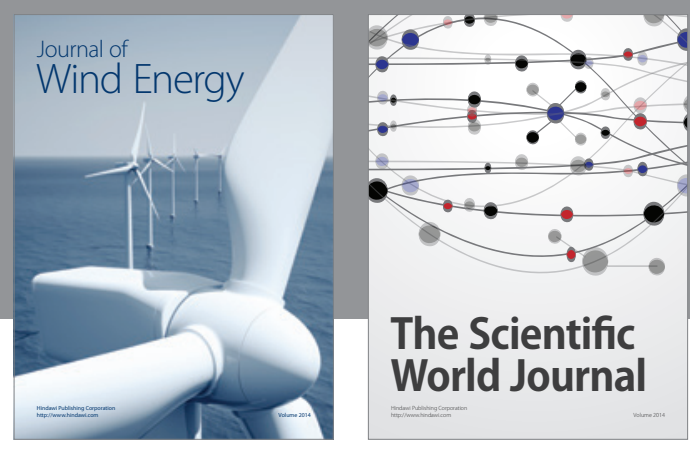

The Scientific World Journal

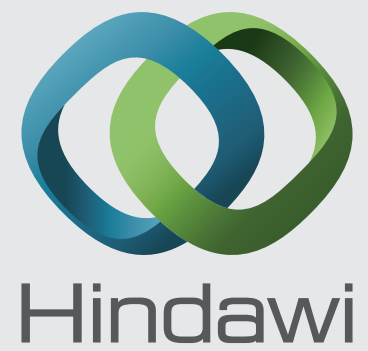

Submit your manuscripts at http://www.hindawi.com
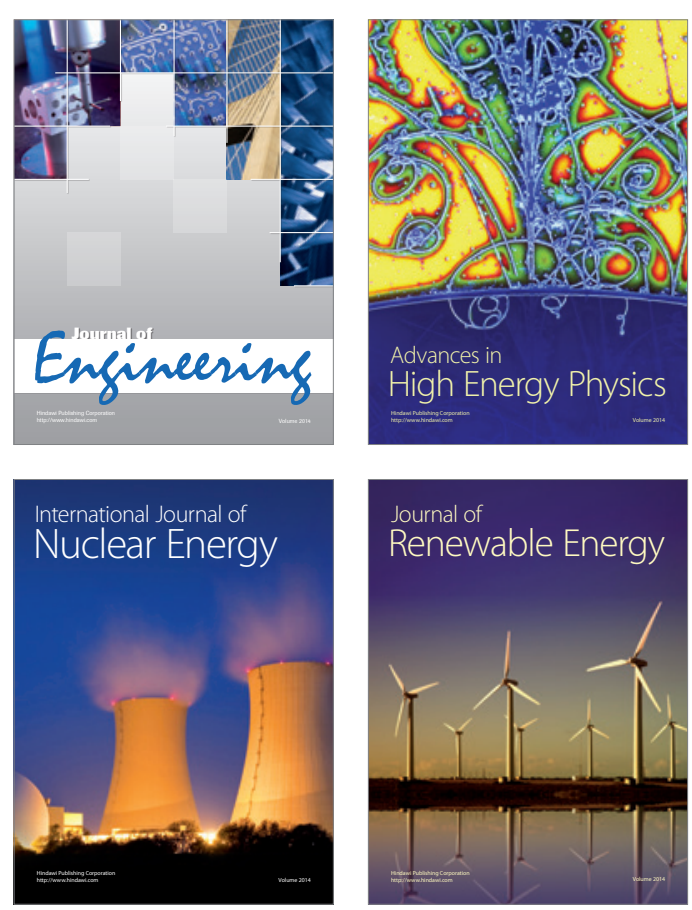

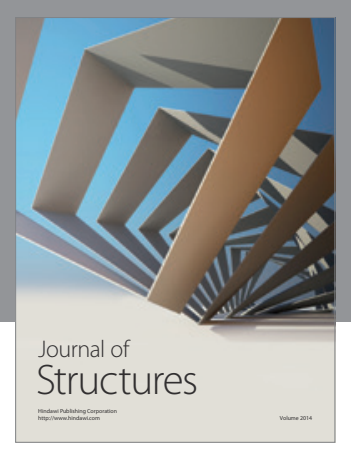

Rotating
Mechinery
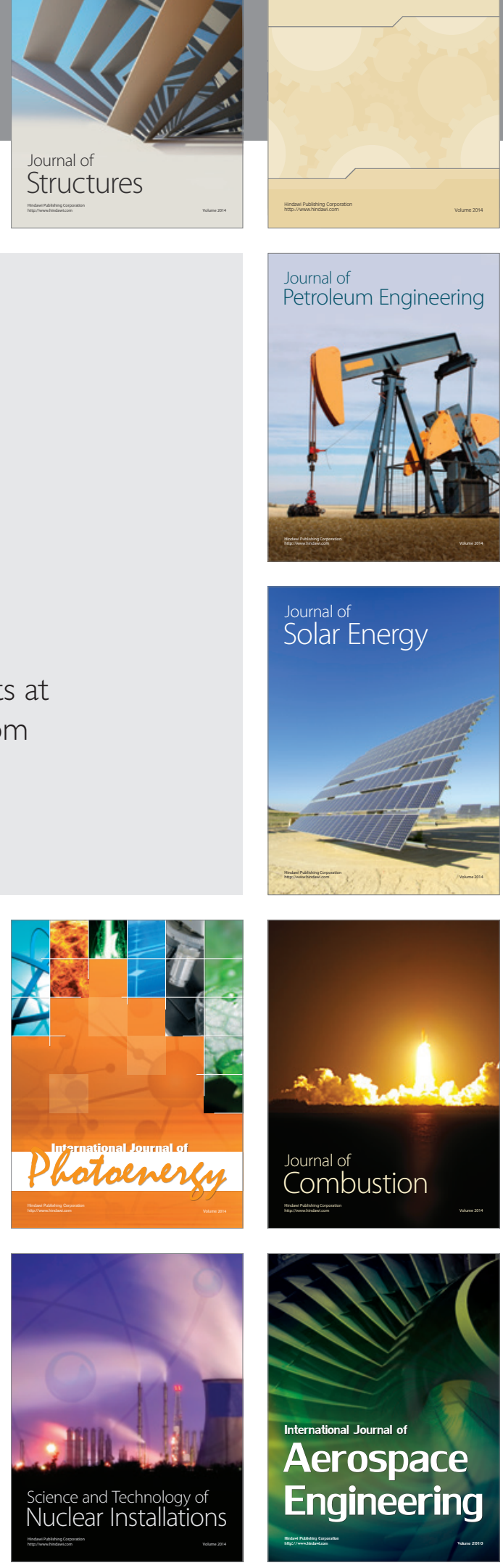